\title{
STUDI LITERATUR IMPLEMENTASI METODE MICROWAVE ASSISTED EXTRACTION (MAE) UNTUK EKSTRAKSI FENOL DENGAN PELARUT ETANOL
}

\author{
Nadya Amelinda Zahar ${ }^{1}$, Neila Zakiah Hanun ${ }^{1}$, Fitria Yulistiani ${ }^{1, *}$, Heriyanto ${ }^{1}$ \\ ${ }^{1}$ Jurusan Teknik Kimia/Program Studi D-IV Teknik Kimia Produksi Bersih, Politeknik Negeri Bandung \\ "E-mail: fitria.yulistiani@ polban.ac.id
}

\begin{abstract}
ABSTRAK
Ekstraksi kandungan fenol menggunakan metode Microwave Assisted Extraction (MAE) dengan pelarut etanol telah banyak dilakukan dengan berbagai kondisi operasi. MAE adalah metode ekstraksi dengan bantuan gelombang elektromagnetik berfrekuensi tinggi dengan rentang frekuensi dari 0,3 hingga $300 \mathrm{GHz}$. Tujuan studi literatur ini adalah mendapatkan rasio liquid to solid (L/S), waktu ekstraksi, dan temperatur ekstraksi optimum yang dapat menghasilkan ekstrak fenol paling banyak dari beberapa jenis bahan baku. Studi literatur dilakukan menggunakan metode analisis deskriptif dengan cara mengumpulkan data serta mengolah data menggunakan perhitungan Mean Squared Error (MSE). Hasil studi literatur menunjukkan bahwa nilai optimum bergantung pada bahan baku yang digunakan. Rasio L/S yang optimum sebesar 17,5/1 (v/w) pada akar manis. Waktu ekstraksi yang optimum sebesar 1,5 menit pada daun sirih merah, 22 menit pada rambut jagung, 6 menit pada akar manis, dan 30 menit pada daun kelor. Temperatur ekstraksi yang optimum sebesar $40^{\circ} \mathrm{C}$ pada daun sirih merah dan $180^{\circ} \mathrm{C}$ pada daun kelor.
\end{abstract}

Kata kunci: microwave assisted extraction, fenol, etanol, rasio L/S, waktu, temperatur

\begin{abstract}
The phenol content was extracted using the Microwave-Assisted Extraction (MAE) method with ethanol solvent under various conditions. MAE is an extraction method with the help of highfrequency electromagnetic waves with a frequency range from 0.3 to $300 \mathrm{GHz}$. The purpose of this literature review is to figure out what liquid to solid (L/S) ratio, extraction time, and optimum extraction temperature will yield the most phenol extract from various types of raw materials. This literature study was carried out using a descriptive analysis method, with data collected and processed by looking at the Mean Squared Error (MSE) value obtained. According to the findings, the raw materials determine the best condition which gives the highest extract value. In licorice, the optimal L/S ratio is 17.5/1 (v/w). The optimal extraction time for red betel leaf was 1.5 minutes, 22 minutes for corn silk, 6 minutes for licorice, and 30 minutes for Moringa leaves. The optimum extraction temperature for red betel leaf was $40^{\circ} \mathrm{C}$, and for Moringa leaf was $180^{\circ} \mathrm{C}$.
\end{abstract}

Keywords: microwave assisted extraction, phenol, ethanol, L/S ratio, time, temperature

\section{PENDAHULUAN}

Fenol merupakan senyawa yang terkandung dalam tanaman dan dapat diambil menggunakan proses ekstraksi. Senyawa fenol memiliki korelasi yang kuat dan positif terhadap potensi antioksidan dari tanaman. Ketika dimasukkan ke dalam makanan, senyawa fenol akan mempertahankan kualitas makanan dan mengurangi risiko timbulnya beberapa penyakit. Karena manfaat senyawa fenol tersebut, banyak peneliti yang melakukan kajian terhadap proses ekstraksi fenol yang dapat menghasilkan yield sebesar-besarnya.

Salah satu metode ekstraksi yang banyak dikaji adalah metode Microwave Assisted Extraction (MAE). Metode 
MAE memiliki banyak keuntungan dibandingkan dengan metode ekstraksi lainnya, yaitu waktu ekstraksi yang lebih singkat, menghasilkan yield yang lebih besar, penggunaan energi yang lebih kecil, dan lebih hemat biaya karena berkurangnya jumlah penggunaan pelarut.

MAE adalah metode ekstraksi dengan bantuan gelombang elektromagnetik berfrekuensi tinggi dengan rentang frekuensi dari 0,3 hingga $300 \mathrm{GHz}$. Metode MAE berbeda dengan metode ekstraksi konvensional. Pada metode ekstraksi konvensional, panas menembus perlahan dari luar ke dalam suatu bahan, sedangkan dalam metode MAE, pemanasan muncul tepat di inti bahan yang sedang dipanaskan dan panas menyebar dari dalam ke luar bahan tersebut (Lopez-Avila \& María, 2014). Perbedaan proses pemanasan pada metode ekstraksi konvensional dengan metode MAE ditunjukkan pada Gambar 1.

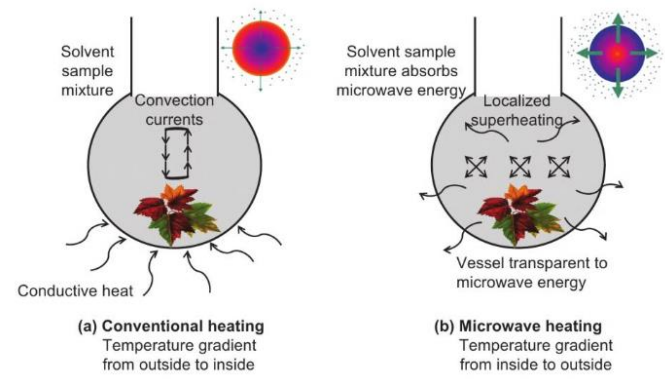

Gambar 1. Perbedaan Pemanasan pada

Ekstraksi Konvensional dan Microwave

Sumber : (Destandau, Michel, \& Elfakir, 2013)

Prinsip metode MAE didasarkan pada efek langsung gelombang mikro pada molekul material. Transformasi energi elektromagnetik menjadi energi panas terjadi oleh dua mekanisme, yaitu konduksi ionik dan rotasi dipol, baik dalam pelarut dan sampel. Pada banyak aplikasi, kedua mekanisme ini berlangsung secara bersamaan karena efektif mengubah energi gelombang mikro menjadi energi panas (Destandau, Michel, \& Elfakir, 2013).

Pada penelitian Karami, dkk (2014), telah dilakukan perbandingan proses ekstraksi kandungan fenol pada minyak akar manis menggunakan pelarut etanol, metanol, dan air dengan metode soxhlet dan MAE. Penggunaan metode soxhlet menghasilkan yield sebesar 14,49\% dan kandungan fenol sebesar 41,709 mg GAE/g pada kondisi waktu ekstraksi 360 menit. Sementara itu, metode MAE menghasilkan yield sebesar 16,38\% dan kandungan fenol sebesar 47,43 mg GAE/g ketika dilakukan pada waktu ekstraksi selama 6 menit. Pelarut etanol dipilih sebagai pelarut optimum pada penelitian ini karena menghasilkan yield dan kandungan fenol tertinggi diantara pelarut lainnya. Penerapan gelombang mikro pada ekstraksi atau MAE telah terbukti dapat mengurangi waktu ekstraksi dan menghasilkan yield lebih besar dibandingkan dengan metode soxhlet (Karami, dkk., 2014).

Metode MAE menggunakan energi yang lebih kecil dibandingkan dengan metode ekstraksi yang lain. Pada penelitian Rodriguez-Perez, dkk (2016) dilakukan perbandingan metode ekstraksi, yaitu pressurized liquid extraction (PLE) dan MAE pada proses ekstraksi minyak daun kelor menggunakan pelarut etanol dengan waktu ekstraksi selama 20 menit pada suhu dan daya yang sama berturut-turut, yaitu $180^{\circ} \mathrm{C}$ dan $850 \mathrm{~W}$. Penggunaan metode PLE menghasilkan kandungan fenol sebesar 70,55 $\mathrm{mg}$ GAE/g. Sementara itu, metode MAE dapat menghasilkan kandungan fenol yang lebih besar, yaitu $105,70 \mathrm{mg}$ GAE/g (Rodriguez-Perez, dkk., 2016).

Pada penelitian dilakukan kajian penentuan rasio L/S, waktu, dan temperatur optimum yang digunakan pada ekstraksi kandungan fenol 
menggunakan metode MAE pada berbagai bahan baku.

\section{METODE}

Penelitian ini dilakukan dengan metode studi literatur dengan pendekatan systematic literature review. Systematic literature review merupakan metode penelitian untuk menilai dan mengidentifikasi secara kritis penelitian yang relevan, dan untuk mengumpulkan dan menganalisis data dari penelitian tersebut (Snyder, 2019). Tahapan pelaksanaan studi literatur ini dilakukan dalam beberapa tahap, yaitu merancang review, melakukan peninjauan, analisis, dan menyusun serta menulis review.

Analisis pada masing-masing parameter dilakukan dengan cara membuat persamaan keterkaitan antara parameter dengan yield fenol. Persamaan tersebut kemudian digunakan untuk memperkirakan nilai yield yang didapat apabila nilai parameter yang ditinjau diubah. Nilai yield hasil perhitungan kemudian dibandingkan dengan hasil percobaan dan dilakukan perhitungan nilai Mean Squared Error (MSE). MSE merupakan suatu parameter yang menunjukkan akurasi hasil perhitungan terhadap hasil percobaan. Standar nilai MSE, yaitu sebesar 0\% dengan toleransi 3-6\%.
Makin kecil nilai mean squared error, maka makin akurat pula hasil dari persamaan yang didapatkan. Nilai mean squared error didapatkan dengan menggunakan persamaaan (1)

$$
\mathrm{MSE}=\sum \frac{(\mathrm{At}-\mathrm{Ft})^{2}}{\mathrm{n}}
$$

di mana At merupakan nilai aktual, $\mathrm{Ft}$ merupakan nilai ramalan, dan $\mathrm{n}$ merupakan periode (Saputro \& Purwanggono, 2016).

Pada penelitian dilakukan analisis terhadap ekstraksi fenol dari berbagai bahan, yaitu daun sirih merah, daun petai, daun kelor, akar manis, dan rambut jagung. Tidak semua bahan diekstrak pada kondisi dan parameter yang sama sehingga analisis setiap parameter hanya dilakukan untuk beberapa jenis bahan baku saja.

\section{HASIL DAN PEMBAHASAN}

\section{Rasio Liquid to Solid (L/S) Optimum}

Dari berbagai sumber literatur hasil penelitian yang ada, bahan yang memiliki data hasil variasi rasio L/S yang cukup lebar adalah akar manis (Karami, dkk., 2014). Pengaruh rasio L/S terhadap yield fenol pada akar manis dijadikan persamaan umum yang hendak digunakan untuk memperkirakan yield fenol pada bahan lainnya. Adapun pengaruh rasio L/S terhadap yield fenol ditunjukkan dalam Gambar 2.

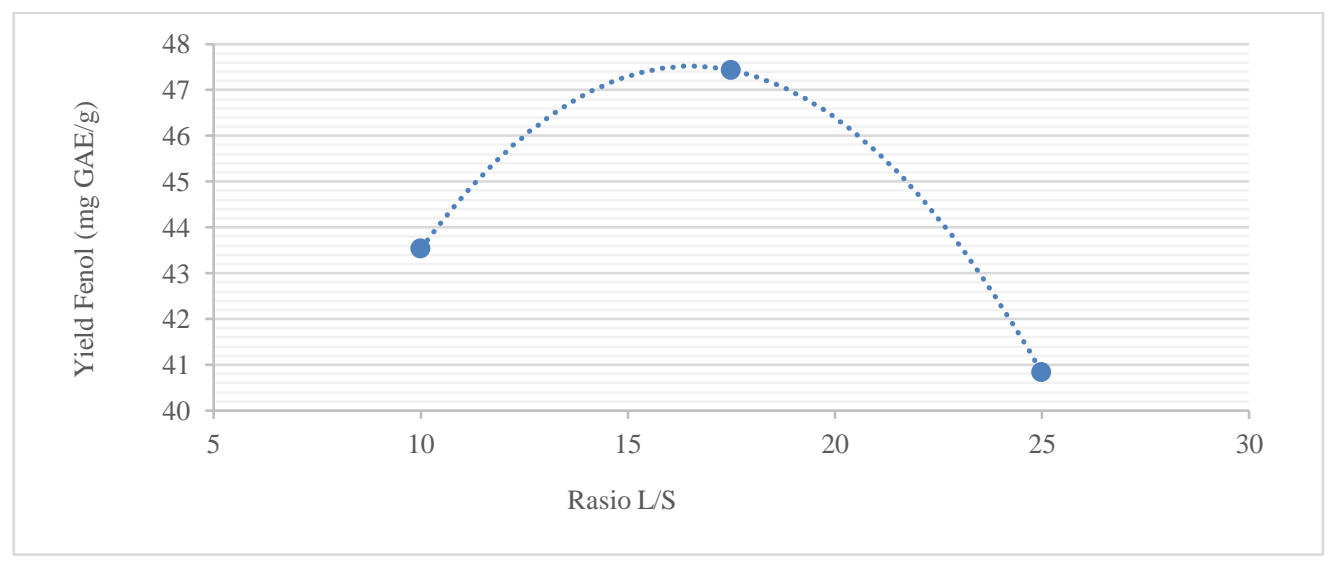

Gambar 2. Grafik Yield Fenol Terhadap Rasio L/S pada Akar Manis 
Persamaan yang didapatkan dari grafik tersebut berupa persamaan (2). $y=-0,0933 x^{2}+3,0867 x+21,997$
Persamaan (2) digunakan untuk memperkirakan yield fenol dari akar manis pada rasio L/S yang berbeda (Gambar 3).

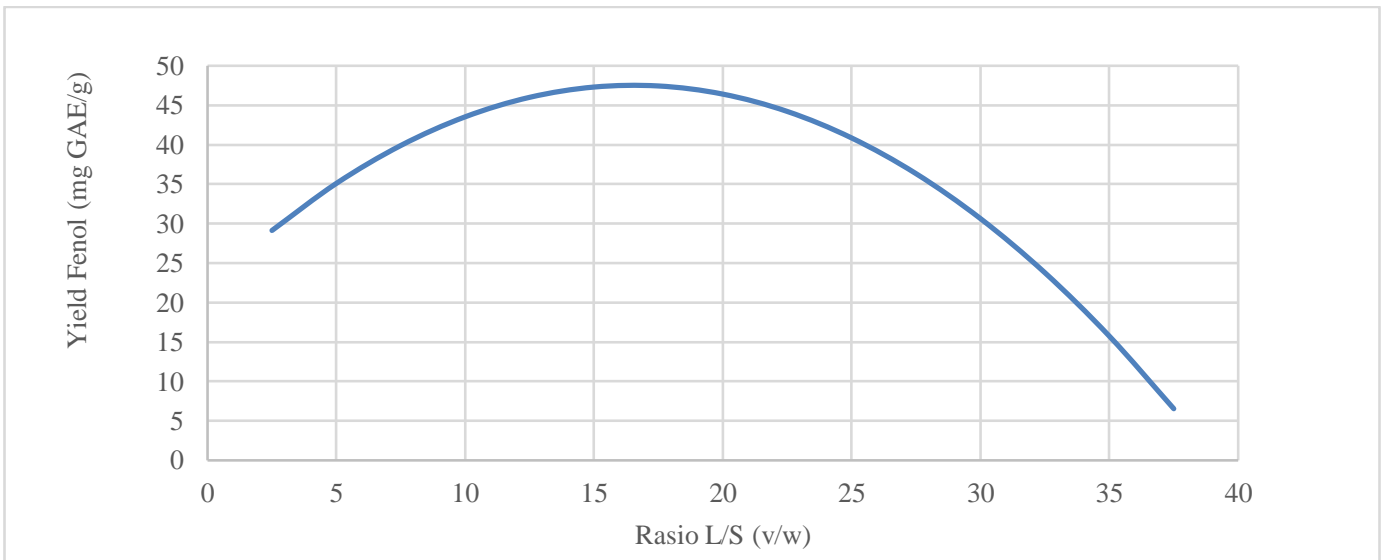

Gambar 3. Grafik Yield Fenol Terhadap Rasio L/S Berdasarkan Persamaan Bahan Akar Manis

Berdasarkan Gambar 3, yield fenol maksimum yang diekstrak menggunakan pelarut etanol pada bahan akar manis dapat diperoleh pada rasio L/S sebesar 17,5/1 (v/w).

Ketika persamaan (1) digunakan untuk memperkirakan yield fenol pada bahan yang berbeda, ternyata nilai MSE yang diperoleh $>6 \%$. Hal tersebut dapat disebabkan oleh perbedaan kondisi operasi penelitian serta perbedaan karakteristik kandungan awal fenol pada masing-masing bahan. Sehingga persamaan yield optimum ini tidak dapat digunakan untuk bahan selain akar manis.

\section{Waktu Operasi Optimum}

Pengaruh waktu operasi terhadap fenol yang dihasilkan pada proses ekstraksi pada berbagai bahan digambarkan pada Gambar 4.

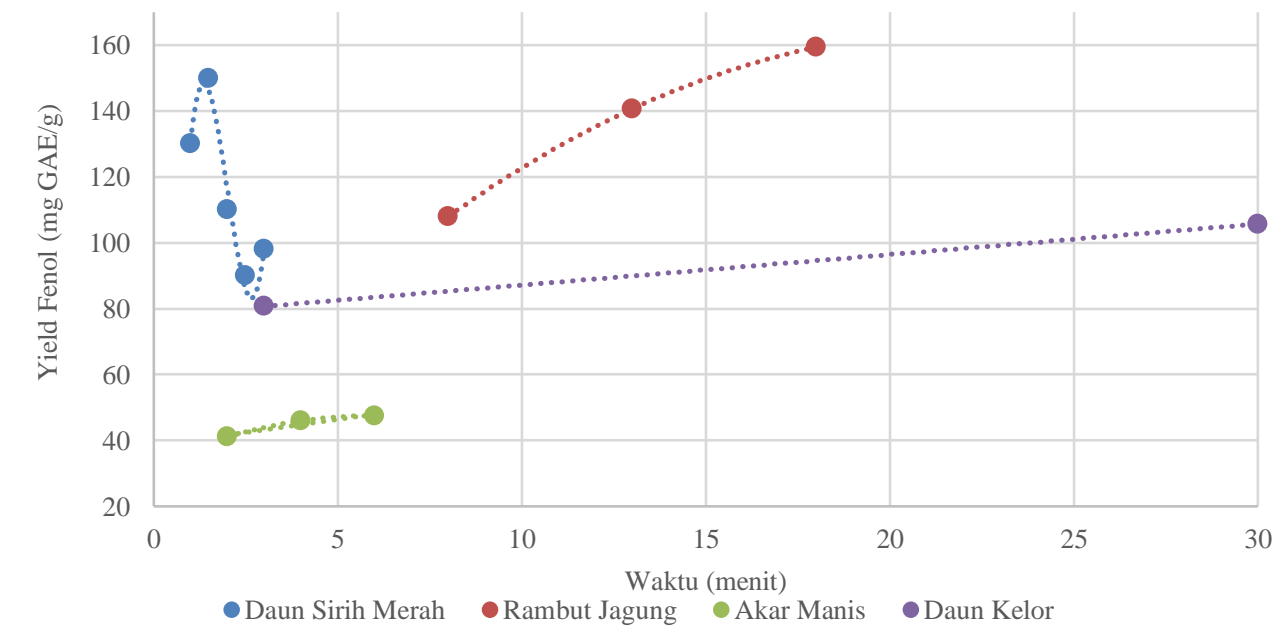

Gambar 4. Grafik Yield Fenol Terhadap Waktu pada Setiap Bahan 
Persamaan-persamaan yang didapatkan dari Gambar 4 dapat dilihat pada Tabel 1.

Tabel 1. Persamaan Garis dari Setiap Bahan

\begin{tabular}{cc}
\hline Bahan & Persamaan Garis \\
\hline $\begin{array}{c}\text { Daun Sirih } \\
\text { Merah }\end{array}$ & $\mathrm{y}=58,667 \mathrm{x}^{3}-353,14 \mathrm{x}^{2}+633,9 \mathrm{x}-$ \\
Rambut & $\mathrm{2} 08,4$ \\
Jagung & $\mathrm{y}=-0,2774 \mathrm{x}^{2}+12,355 \mathrm{x}+26,87$ \\
Akar Manis & $\mathrm{y}=-0,425 \mathrm{x}^{2}+4,99 \mathrm{x}+32,79$ \\
Daun Kelor & $\mathrm{y}=0,9263 \mathrm{x}+77,911.5$ \\
\hline
\end{tabular}

Persamaan-persamaan pada Tabel 1 selanjutnya digunakan pada memperkirakan yield fenol berbagai bahan dan didapatkan Gambar 5.

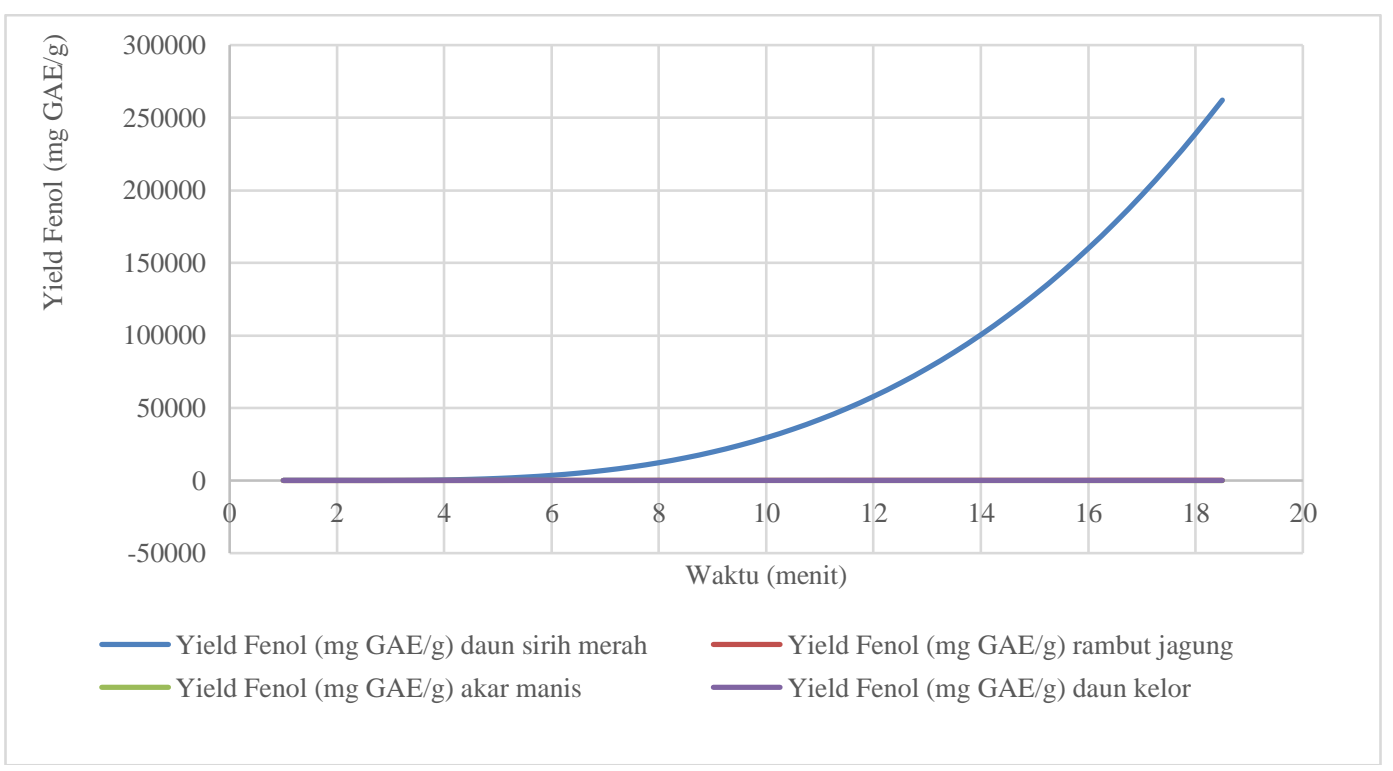

Gambar 5. Grafik Yield Fenol Terhadap Waktu pada Setiap Bahan Berdasarkan Persamaan

Persamaan yang didapatkan pada Tabel 1 tidak dapat dipertukarkan untuk jenis bahan yang berbeda karena MSE > $6 \%$. Oleh karena itu, perhitungan waktu ekstraksi optimum dilakukan menggunakan persamaan bahan masingmasing. Hasil perhitungan waktu ekstraksi optimum dapat dilihat pada Tabel 2.

Tabel 2. Waktu Ekstraksi Optimum Berdasarkan Persamaan

\begin{tabular}{cc}
\hline Bahan & $\begin{array}{c}\text { Waktu Ekstraksi } \\
\text { Optimum (menit) }\end{array}$ \\
\hline Daun Sirih Merah & 1,5 \\
Rambut Jagung & 22 \\
Akar Manis & 6 \\
Daun Kelor & 30 \\
\hline
\end{tabular}

Waktu ekstraksi optimum telah didapatkan dari persamaan. Namun, pada penelitian daun sirih merah, terjadi penurunan pada menit ke-2, lalu terjadi kenaikan yield fenol sampai waktu yang lama sehingga rentang waktu ekstraksi perlu diperbesar untuk mendapatkan waktu ekstraksi optimum sebenarnya. Pada penelitian daun kelor juga rentang waktu ekstraksi perlu ditambahkan karena masih terjadi penambahan yield fenol setelah menit ke-30.

\section{Temperatur Ekstraksi Optimum}

Menurut Destandau, dkk (2013), penggunaan daya yang besar pada microwave sebanding dengan 
temperatur sistemnya, maka jika makin besar daya microwave, maka makin besar pula temperatur sistemnya. Meningkatnya temperatur menyebabkan peningkatan kadar fenol sampai pada temperatur tertentu kemudian menurun seiring dengan peningkatan temperatur (Riadini, 2015). Pengaruh temperatur terhadap yield fenol yang dihasilkan dapat dilihat pada Gambar 6.

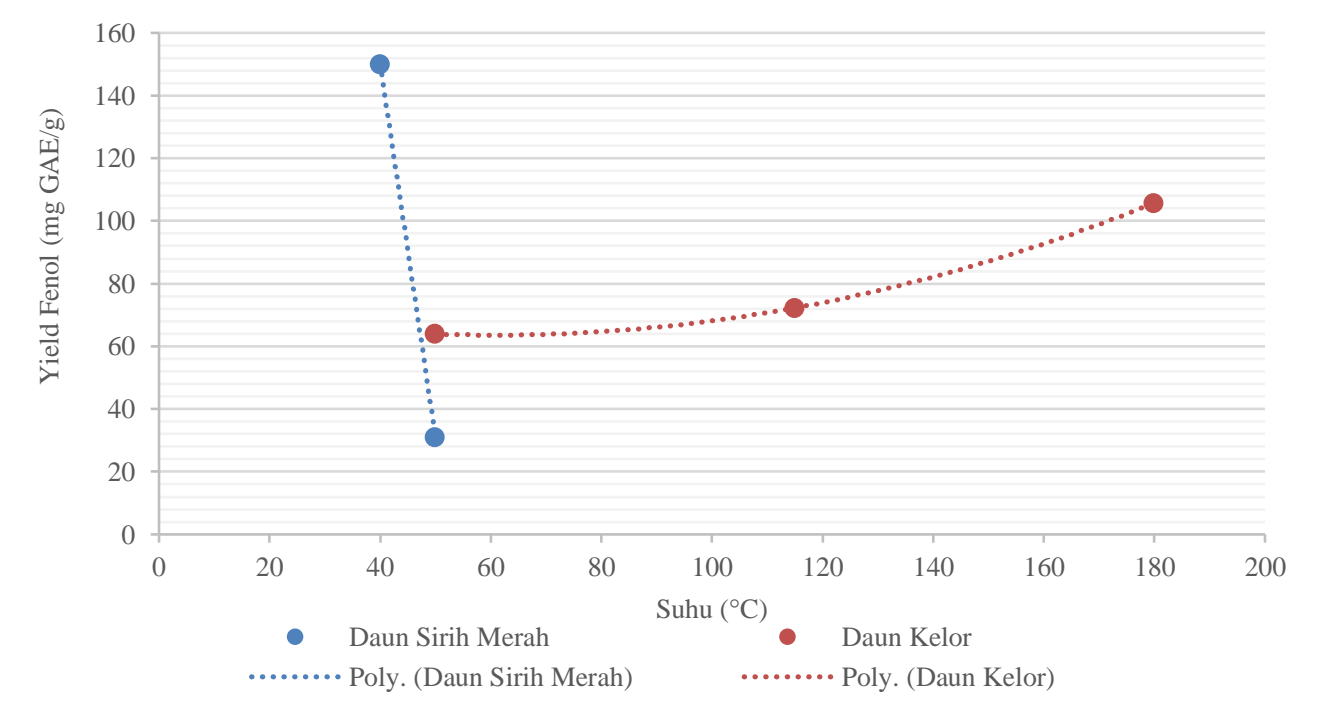

Gambar 6. Grafik Yield Fenol Terhadap Temperatur pada Setiap Bahan

Persamaan-persamaan yang didapatkan dari Gambar 6 dapat dilihat pada Tabel 3.

Tabel 3. Persamaan Garis dari Setiap Bahan

\begin{tabular}{cc}
\hline Bahan & Persamaan Garis \\
\hline $\begin{array}{c}\text { Daun Sirih } \\
\text { Merah }\end{array}$ & $\mathrm{y}=-11,9 \mathrm{x}+626$ \\
Daun Kelor & $\mathrm{y}=0,003 \mathrm{x}^{2}-0,3616 \mathrm{x}+74,588$ \\
\hline
\end{tabular}

Persamaan-persamaan pada Tabel 3 digunakan untuk memperkirakan yield fenol pada suhu yang berbeda seperti ditunjukkan pada Gambar 7.

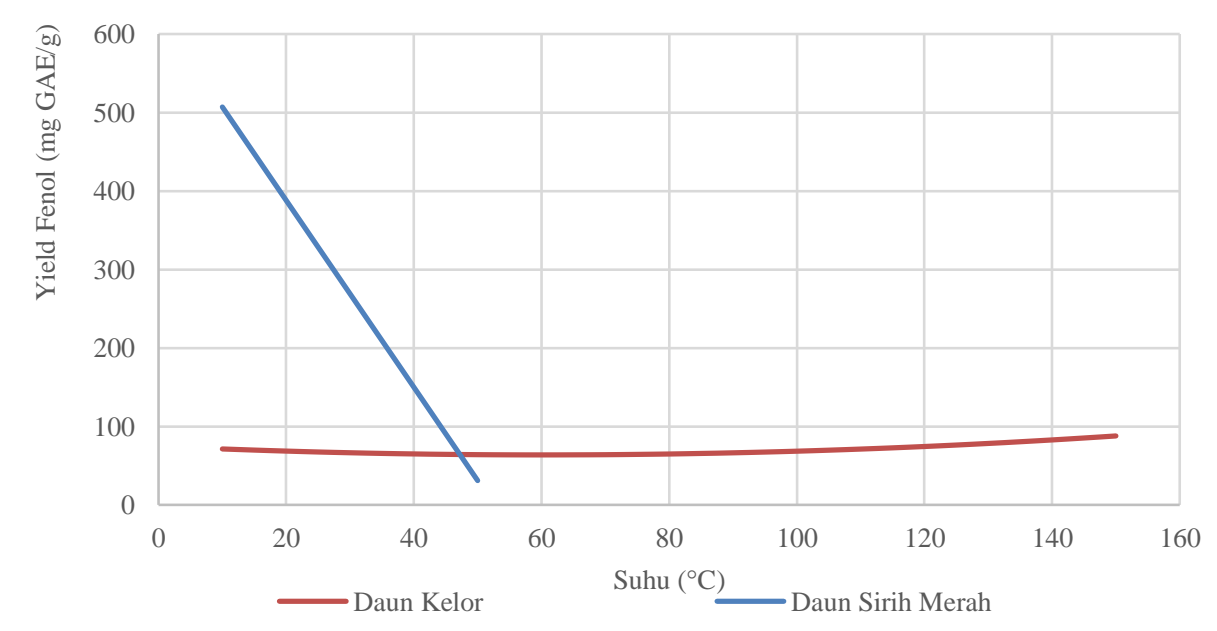

Gambar 7 Grafik Yield Fenol Terhadap Temperatur pada Setiap Bahan Berdasarkan Persamaan 
Persamaan yang didapatkan merupakan dari bahan daun sirih merah dan bahan daun kelor. Namun, persamaan yang digunakan hanya persamaan daun kelor karena daun kelor memiliki variasi temperatur lebih dari dua titik. Persamaan daun kelor yang didapatkan tidak dapat digunakan untuk bahan lainnya karena nilai MSE yang tidak sesuai dengan standar.

Berdasarkan persamaan yang didapatkan, temperatur optimum untuk mengekstraksi fenol dalam bahan daun sirih merah dan daun kelor berturutturut, yaitu pada temperatur $40^{\circ} \mathrm{C}$ dan $180^{\circ} \mathrm{C}$.

\section{SIMPULAN}

Dari studi literatur yang telah dilakukan, dapat diambil kesimpulan sebagai berikut:

1. Rasio liquid to solid (L/S) optimum pada ekstraksi kandungan fenol dari akar manis menggunakan metode $M A E$, yaitu $17,5 / 1$ (v/w).

2. Waktu ekstraksi optimum pada ekstraksi kandungan fenol menggunakan metode $M A E$ berbeda pada setiap bahan, yaitu:

- Daun sirih merah dengan waktu 1,5 menit

- Rambut jagung dengan waktu 22 menit

- Akar manis dengan waktu 6 menit

- Daun kelor dengan waktu 30 menit

3. Temperatur ekstraksi optimum pada ekstraksi kandungan fenol menggunakan metode $M A E$ berbeda pada setiap bahan, yaitu:

- Daun sirih merah dengan temperatur $40^{\circ} \mathrm{C}$

- Daun kelor dengan temperatur $180^{\circ} \mathrm{C}$

Studi literatur ini dapat diterapkan dengan beberapa saran sebagai berikut:
1. Diperlukan langkah proses penentuan kandungan awal fenol pada setiap bahan dalam penelitian yang dilakukan di laboratorium.

2. Dilakukan variasi nilai parameter seperti rasio L/S, waktu, dan termperatur ekstraksi pada setiap bahan tanaman dalam penelitian yang dilakukan di laboratorium.

3. Dalam penggunaan persamaan, rentang temperatur optimum perlu diperbesar karena masih terdapat adanya kenaikan nilai yield setelah melewati temperatur optimum dalam penelitian.

\section{DAFTAR RUJUKAN}

Buanasari, Eden, W., \& Solichah, A. (2017). Extraction of Phenolic Compounds from Petai Leaves (Parkia speciosa Hassk.) using Microwave and Ultrasound Assisted Methods. Jurnal Bahan Alam Terbarukan, 6(1), 25-31.

Destandau, E., Michel, T., \& Elfakir, C. (2013). Microwave-Assisted Extraction, Chapter 4. France: Institut de Chimie Organique et Analytique, Université d'Orléans.

Islamudin, A., Ara, D., Gita, T., \& Hayun. (2018). Effect of Microwave Assisted Extraction Conditions on Mineral and Antioxidant Properties of Moringa oleifera Lam. International Journal of Research in Pharmacy and Science, 8(1), 26-33.

Karami, Z., Emam-Djomeh, Z., Mirzaee, H., Khomeiri, M., Mahoonak, A., \& Aydani, E. (2014). Optimization of Microwave Assisted Extraction (MAE) and Soxhlet Extraction of Phenolic Compound from Licorice Root. Journal of Food Science and Technology, 52(6). 
Kristanti, Y., Widarta, I., \& Permana, I. (2019). Pengaruh Waktu Ekstraksi dan Konsentrasi Etanol Menggunakan Metode Microwave Assisted Extraction (MAE) Terhadap Aktivitas Antioksidan Ekstrak Rambut Jagung (Zea mays L.). Jurnal Ilmu dan Teknologi Pangan, 8(1), 94-103.

Lopez-Avila, V., \& María, C. (2014). Microwave-Assisted Extraction. Waltham: Elsevier Reference Module in Chemistry, Molecular Sciences and Chemical Engineering.

Nisa, G., Nugroho, W., \& Hendrawan, Y. (2014). Ekstraksi Daun Sirih Merah (Piper crocatum) dengan Metode Microwave Assisted Extraction (MAE). Jurnal Bioproses Komoditas Tropis, 2(1).

Riadini, R. K. (2015). Uji Aktivitas Antioksidan Ekstrak Daun Sambung Nyawa (Gynura procumbens (Lour.) Merr.) Berdasarkan Perbedaan Metode Ekstraksi dan Umur Panen. Yogyakarta: Universitas Atma Jaya Yogyakarta.

Rodriguez-Perez, C., Gilbert-Lopez, B., Mendiola, J., Quirantes-Pine, R., Segura-Carretero, A., \& Ibanez, E. (2016). Optimization of Microwave-Assisted Extraction and Pressurized Liquid Extraction of Phenolic
Compounds from Moringa oleifera Leaves by Multiresponse Surface Methodology. Electrophoresis Journal, 1-9.

Saputro, A., \& Purwanggono, B. (2016). Peramalan Perencanaan Produksi Semen dengan Metode Exponential Smoothing pada PT Semen Indonesia. Industrial Engineering Online Journal, 5(4).

Snyder, H. (2019). Literature Review as A Research Methodology : An Overview and Guidelines. Journal of Business Research, 333-339.

Vijayalakshmi, U., \& Shourie, A. (2015). Evaluation of Different Methods for Extraction of Antioxidant Phenolic Compounds from Glycyrrhiza Glabra Roots. World Journal of Pharmaceutical Research, 4(10), 1524-1537.

Yasa, I. G., Putra, N. K., \& Wiadnyani, A. A. (2019). Pengaruh Konsentrasi Etanol Terhadap Aktivitas Antioksidan Ekstrak Daun Sirih Merah (Piper crocatum Ruitz \& Pav) Menggunakan Metode Microwave Assisted Extraction (MAE). Jurnal Ilmu dan Teknologi Pangan, 8(3), 278284. 